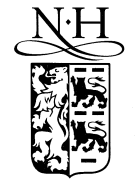

ELSEVIER

\title{
Novel emulsion process for synthesizing submicron lithium nickel oxide powder used in lithium ion batteries
}

\author{
Chung-Hsin Lu *, Wei-Cheng Lee \\ Department of Chemical Engineering, National Taiwan University, Taipei, Taiwan
}

Received 29 September 1998; received in revised form 25 January 1999; accepted 29 January 1999

\begin{abstract}
A novel water-in-oil emulsion process has been successfully developed to prepare submicron lithium nickel oxide $\left(\mathrm{LiNiO}_{2}\right)$ powder. The aqueous solution containing lithium and nickel cations was well emulsified in kerosene by adding sorbitan monooleate as surfactant. After calcining the dried precursors at $800^{\circ} \mathrm{C}$ for $2 \mathrm{~h}$, highly crystalline monophasic $\mathrm{LiNiO}_{2}$ powder with $R 3 \mathrm{~m}$ structure was achieved. In comparison with the conventional solid state process, this emulsion process significantly reduced the reaction time for preparing $\mathrm{LiNiO}_{2}$, which is attributed to improved homogeneity of constitute cations and enhanced reactivity in the obtained precursors. The curtailed reaction time in the emulsion process also facilitated the reduction of the particle size of $\mathrm{LiNiO}_{2}$ powder. Fine grains of $\mathrm{LiNiO}_{2}$ powder with a narrow particle size distribution ranging from 0.2 to $0.3 \mu \mathrm{m}$ were obtained in this study. (C) 1999 Elsevier Science B.V. All rights reserved.
\end{abstract}

Keywords: Emulsion; Synthesis; $\mathrm{LiNiO}_{2}$; Microstructure; Submicron powder; Lithium ion batteries

\section{Introduction}

Nowadays, the demand for rechargeable batteries with high energy density and high voltage has increased rapidly due to the advancement and popularity of portable electronic devices. Layered lithium nickel oxide $\mathrm{LiNiO}_{2}$ has been reported to have great commercial potential for use in the cathode material for the $4-\mathrm{V}$ secondary lithium ion batteries because of its high electricity capacity, long cycle life, moderate rate capabilities, and low cost [1-3]. Preparation of $\mathrm{LiNiO}_{2}$ ceramic powder is usually achieved by solid state reaction at high temperature with long calcining time (usually more than $12 \mathrm{~h}$ ) [4,5]. How-

\footnotetext{
* Corresponding author. Tel.: + 886-2-3635230; Fax: + 886-23623040
}

ever, the stoichiometric $\mathrm{LiNiO}_{2}$ is difficult to obtain under high reaction temperature after long calcining time, because $\mathrm{LiNiO}_{2}$ tends to decompose to become the disordered $\mathrm{Li}_{1-x} \mathrm{Ni}_{1+x} \mathrm{O}_{2}$ compounds under such conditions [6,7]. The structural disorder in the $\mathrm{LiNiO}_{2}$ matrix will impede the intercalation and the de-intercalation of lithium ions, thereby deteriorating the performance and utilization of $\mathrm{LiNiO}_{2}$ [3]. Besides, the prolonged reaction time and the elevated reaction temperature result in more energy consumption and cause the powder to become coarsened. Therefore, developing a new process which makes possible the synthesis of $\mathrm{LiNiO}_{2}$ under low reaction temperatures and short heating time is important from the view points of the economy and practical usage.

The purpose of this study is to develop a new emulsion process for synthesizing $\mathrm{LiNiO}_{2}$ powder 


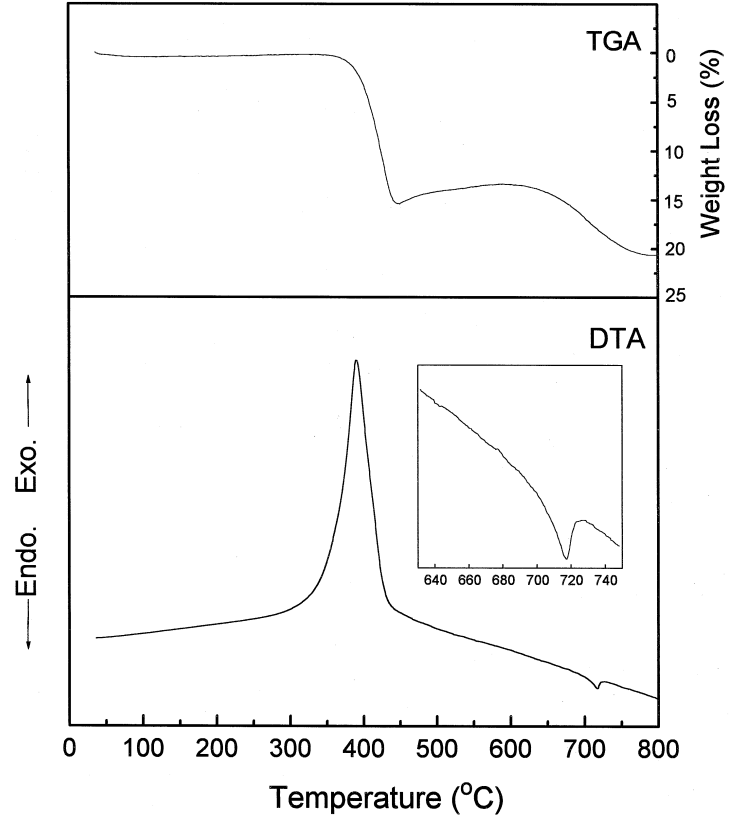

Fig. 1. TGA and DTA curves of the $\mathrm{LiNiO}_{2}$ precursors prepared by the emulsion process.

which has fine particle size, narrow particle size distribution, and high crystallinity. The emulsion technique is one type of soft chemistry methods [8]. The authors have utilized the similar emulsion process to successfully prepare monophasic and fine particles of $\mathrm{PbTiO}_{3}$ and $\mathrm{ZnO}[9,10]$. In the emulsion process, appropriate ratios of cations are dissolved in water, and then the aqueous solution is mixed with an immiscible oil phase. Through adding an appropriate surfactant and using emulsifying treatment, the aqueous solution can be well dispersed to form microscopic liquid droplets in the oil phase. Since each droplet acts as an independent reactor, the morphology of powder can be easily controlled by the droplet size. In this study, the emulsion process was developed to prepare $\mathrm{LiNiO}_{2}$ powder. The formation processes of the emulsion-derived powder was examined for determining the appropriate heating conditions for synthesizing $\mathrm{LiNiO}_{2}$. The effects of heating processes on the purity and morphology of $\mathrm{LiNiO}_{2}$ powder were also investigated. Furthermore, the reaction processes and microstructure of $\mathrm{LiNiO}_{2}$ powder prepared by the emulsion process were compared with those prepared by the conventional solid state reaction.

\section{Experimental}

In the emulsion process, kerosene was used as the continuous oil phase, the aqueous solution as the dispersed phase, and sorbitan monooleate as surfactant. The aqueous phase was prepared by dissolving appropriate amounts of lithium acetate and nickel acetate in de-ionized water. Both of the concentrations of lithium and nickel cations were $0.4 \mathrm{M}$. Sorbitan monooleate ( $5 \mathrm{wt} . \%$ ) was added to the oil phase for increasing the stability of emulsion. Then the prepared aqueous phase and oil phase were mixed together with a water/oil volume ratio of 1:5. The mixed solutions were agitated by a homogenizer with a rate of $250 \mathrm{rpm}$ for $2 \mathrm{~h}$ to obtain homogeneous water-in-oil emulsion. The prepared emulsion was then heated on a hot plate to evaporate the oil phase as well as the water phase. The dried materials were calcined at $400^{\circ} \mathrm{C}$ for $1 \mathrm{~h}$ in a crucible with a lid in a box furnace to burn away the residual organic species (kerosene and surfactant) to obtain the precursors of $\mathrm{LiNiO}_{2}$. To examine the reaction process and weight loss of the precursors, the cal-

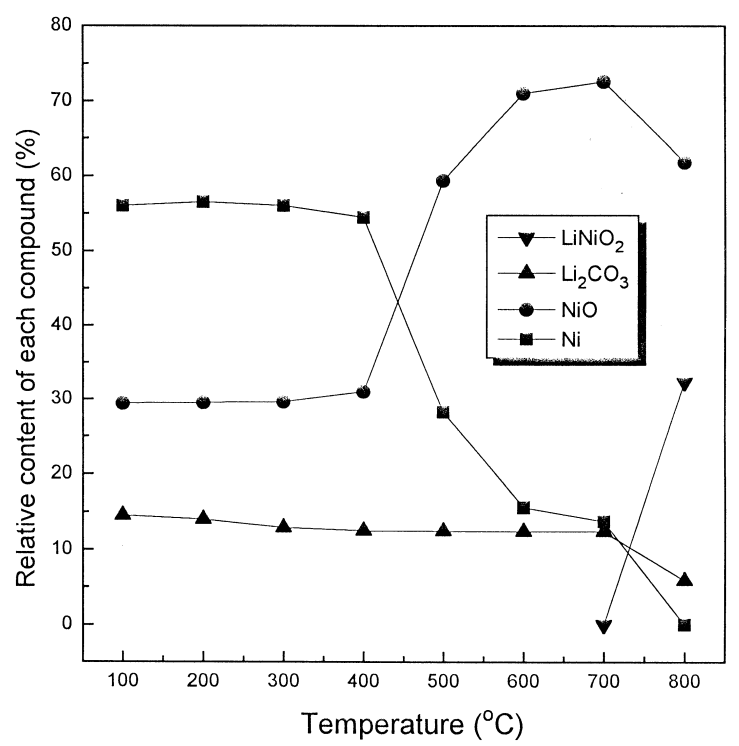

Fig. 2. Relative content of each compound present in the emulsion-derived $\mathrm{LiNiO}_{2}$ precursors quenched at various temperatures. 
cined precursors were subjected to the thermal analysis (DTA and TGA) at a heating rate of $10^{\circ} \mathrm{C} / \mathrm{min}$. In addition, the precursors were calcined at elevated temperatures under a flowing oxygen stream. X-ray diffraction (XRD) analysis was performed to identify the compounds formed in the calcined powder. Infrared spectrometry (IR) was used to examine the organic species left in the products. Scanning electron microscopy (SEM) was carried out to observe the microstructures and particle size of the obtained powder.

\section{Results and discussion}

Fig. 1 shows the DTA and TGA results for the emulsion-derived precursors of $\mathrm{LiNiO}_{2}$. In the DTA curve, one large exothermic peak and one small endothermic peak are observed around 400 and $720^{\circ} \mathrm{C}$, respectively. In the TGA curve, the weight of the sample shows a steep drop around $400^{\circ} \mathrm{C}$. This weight loss is attributed to the combustion of residual organic species, which also causes the large exothermic reaction in DTA. Between 430 and $600^{\circ} \mathrm{C}$, the weight of the sample shows a trend of increase. At elevated temperatures the weight of the sample tends to decrease again.

In order to elucidate the reaction mechanism of the emulsion-derived precursors, the specimens were quenched during heating process, and then examined by XRD. The relative contents of various compounds at different temperatures are plotted in Fig. 2. The relative content of each compound was calculated by dividing the diffraction intensity of the strongest line for certain compound to the sum of the diffraction intensity of the strongest line of all compounds

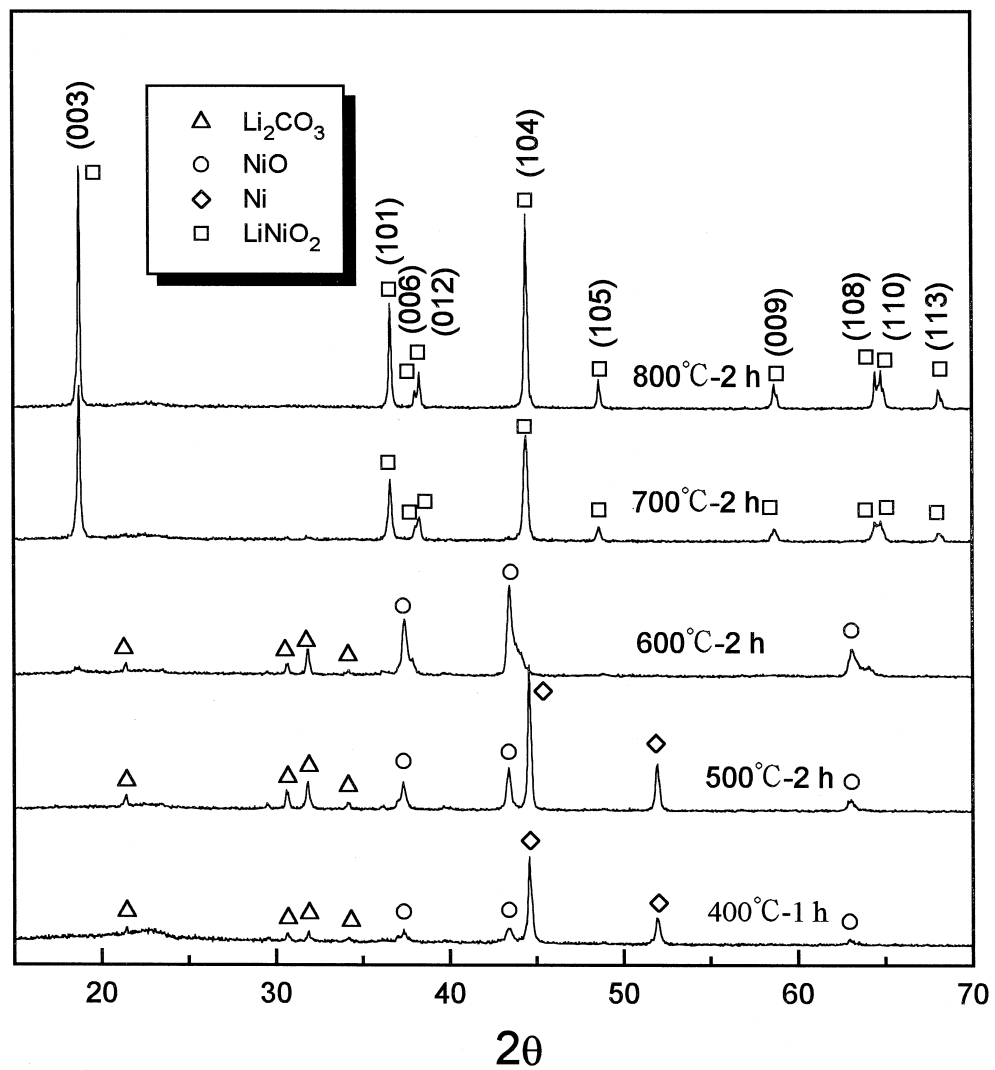

Fig. 3. XRD patterns of the emulsion-derived $\mathrm{LiNiO}_{2}$ precursors calcined at various temperatures. 
present. As shown in this figure, the emulsion-derived precursors are composed primarily of $\mathrm{Ni}, \mathrm{NiO}$ and $\mathrm{Li}_{2} \mathrm{CO}_{3}$. For preparing the precursors of $\mathrm{LiNiO}_{2}$, the dried materials are calcined at $400^{\circ} \mathrm{C}$ in a crucible with a lid in a box furnace. During the calcination process, due to the burning the residual organic species (kerosene and surfactant), $\mathrm{CO}$ and $\mathrm{CO}_{2}$ are produced in the crucible and the furnace. Therefore, in the reducing atmosphere, the nickel-containing species are reduced to form nickel. The phases of the specimens remain almost unchanged at temperature below $400^{\circ} \mathrm{C}$. However, at above $400^{\circ} \mathrm{C}$ the relative content of $\mathrm{Ni}$ starts to decrease with an increase in the relative content of $\mathrm{NiO}$, implying that the oxidization of $\mathrm{Ni}$ has occurred. As for $\mathrm{Li}_{2} \mathrm{CO}_{3}$, its relative content does not change at temperature below $700^{\circ} \mathrm{C}$. On the other hand, the formation $\mathrm{LiNiO}_{2}$ starts to occur from above $700^{\circ} \mathrm{C}$, accompanied with a decrease in the relative contents of all reactants. According to the above results, the weight gain from above $430^{\circ} \mathrm{C}$ as shown on the TGA curve in Fig. 1 is ascribed to the oxidation of $\mathrm{Ni}$ to $\mathrm{NiO}$. The endothermic reaction at around $720^{\circ} \mathrm{C}$ is attributed to the formation of $\mathrm{LiNiO}_{2}$. This endothermic reaction also results in weight loss due to the evolution of carbon dioxide from $\mathrm{Li}_{2} \mathrm{CO}_{3}$.

In order to obtain the pure phase of $\mathrm{LiNiO}_{2}$ powder, the precursors were calcined for $2 \mathrm{~h}$ at different temperatures. The XRD patterns of calcined specimens are shown in Fig. 3. During calcination at temperature ranging from 400 to $600^{\circ} \mathrm{C}$, the main reaction occurring in the precursors is the oxidation reaction of nickel species. However, after heating at $700^{\circ} \mathrm{C}, \mathrm{LiNiO}_{2}$ with $R 3 \mathrm{~m}$ structure is obtained. As the heating temperature is raised to $800^{\circ} \mathrm{C}$, the crystallinity of the $\mathrm{LiNiO}_{2}$ sample further increases, and no more nickel species is observed in XRD. Judging from the XRD pattern, the obtained $\mathrm{LiNiO}_{2}$ powder is monophasic, which is identical to that recorded in JCPDS No. 9-63 [11]. This result reveals that pure phase $\mathrm{LiNiO}_{2}$ was successfully prepared by the emulsion process. In comparison with other studies using the similar temperatures to synthesize $\mathrm{LiNiO}_{2}$ $[2,6,12]$, the heating time $(2 \mathrm{~h})$ in the emulsion process is much shorter than those reported in literature $(6 \mathrm{~h}-48 \mathrm{~h})$.

Infrared spectra for calcined specimens prepared by the emulsion process are shown in Fig. 4a. The

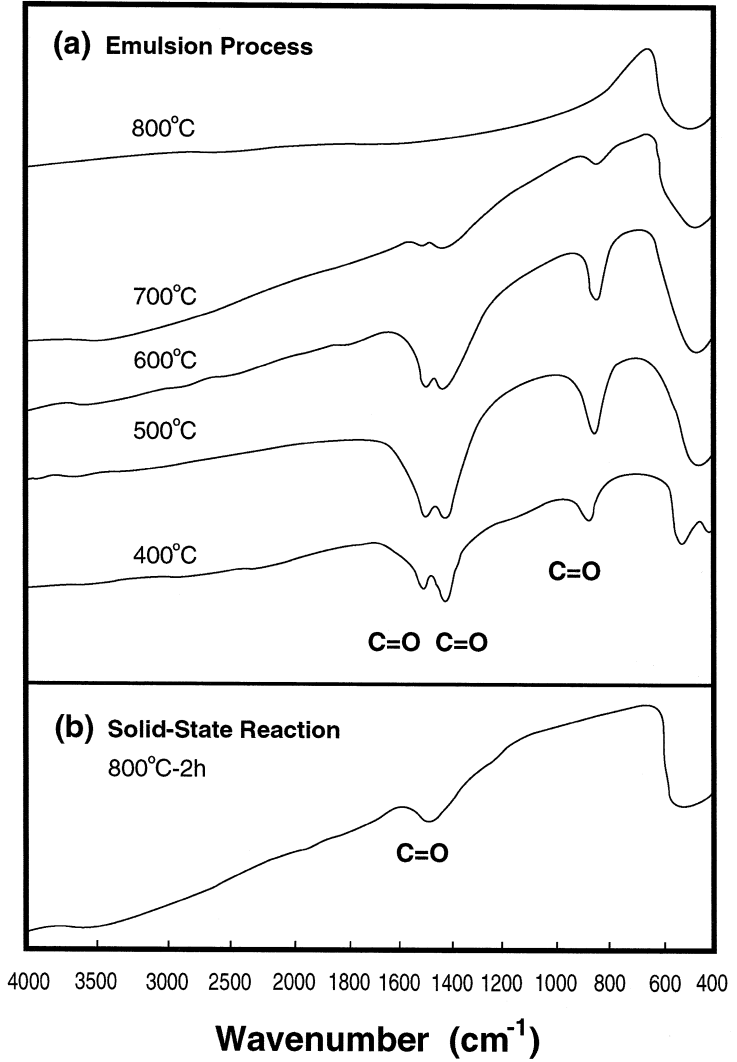

Fig. 4. (a) Infrared spectra of the emulsion-derived $\mathrm{LiNiO}_{2}$ precursors calcined at various temperatures. (b) Infrared spectrum for $\mathrm{LiNiO}_{2}$ powder prepared by the conventional solid state reaction after heating at $800^{\circ} \mathrm{C}$ for $2 \mathrm{~h}$.

bands at 900 and $1400-1600 \mathrm{~cm}^{-1}$ in the samples calcined at $400,500,600$ and $700^{\circ} \mathrm{C}$ indicate the presence of carbonyl groups. The carbonyl groups mainly exist in the unreacted $\mathrm{Li}_{2} \mathrm{CO}_{3}$. The intensities of these bands decrease as the heating temperature increases, showing that the carbonyl groups gradually are burn away. For the sample heated at $800^{\circ} \mathrm{C}$ for $2 \mathrm{~h}$, the carbonyl groups completely disappear, revealing that the reaction between $\mathrm{NiO}$ and $\mathrm{Li}_{2} \mathrm{CO}_{3}$ is complete. This result is consistent with the XRD analysis. As for the band appearing at around 600 $\mathrm{cm}^{-1}$, it is attributed to the characteristic adsorption band of $\mathrm{LiNiO}_{2}$. In order to remove the residual carbonyl groups at lower temperature, the precursors were calcined at $650^{\circ} \mathrm{C}$ for $6 \mathrm{~h}$. It was also found that monophasic $\mathrm{LiNiO}_{2}$ without residual carbonyl groups 
was obtained. On the other hand, $\mathrm{LiNiO}_{2}$ powder was also prepared by the conventional solid state reaction using the mixtures of $\mathrm{Li}_{2} \mathrm{CO}_{3}$ and $\mathrm{NiO}$ as starting materials. Fig. $4 \mathrm{~b}$ shows the infrared spectrum of the specimen prepared by the solid state reaction after heating at $800^{\circ} \mathrm{C}$ for $2 \mathrm{~h}$. The presence of carbonyl groups in Fig. 4b indicates that the formation of $\mathrm{LiNiO}_{2}$ is incomplete. It is found that in the solid state reaction the reaction time at $800^{\circ} \mathrm{C}$ has to increase to $6 \mathrm{~h}$ for the complete reaction of $\mathrm{LiNiO}_{2}$. As a result, in comparison with the solid state reaction, the emulsion process significantly reduces the reaction time required for the complete reaction of $\mathrm{LiNiO}_{2}$. The reduction in reaction time for the formation of $\mathrm{LiNiO}_{2}$ in the emulsion process is mainly attributed to the enhanced reactivity and improved homogeneity of constituent cations in the precursors.

The microstructure of $\mathrm{LiNiO}_{2}$ powder prepared by the emulsion process after calcining at $800^{\circ} \mathrm{C}$ for $2 \mathrm{~h}$ is shown in Fig. 5a. This powder exhibit a homogeneous morphology in a dispersed state. The particle size of this powder is within narrow size distribution in the range of $0.2-0.3 \mu \mathrm{m}$. The obtained $\mathrm{LiNiO}_{2}$ powder exhibits a less-agglomerated morphology and smaller particle size than that prepared by sol-gel process [12]. The microstructure of the $\mathrm{LiNiO}_{2}$ powder obtained by solid state process after heating at $800^{\circ} \mathrm{C}$ for $6 \mathrm{~h}$ is shown in Fig. $5 \mathrm{~b}$. This figure reveals that the latter powder exhibits a faceted shape with a wide particle size distribution ranging from 3 to $5 \mu \mathrm{m}$. Comparing Fig. 5a with b, it is obvious that the emulsion process significantly reduces the particle size of $\mathrm{LiNiO}_{2}$ powder, and also results in $\mathrm{LiNiO}_{2}$ powder with an uniform morphology and a narrow size distribution. The coarsening of $\mathrm{LiNiO}_{2}$ powder in the solid state reaction is mainly caused by the prolonged heating time and the large grains of starting mixtures used. As a consequence, this emulsion process is confirmed to be an effective method to synthesize $\mathrm{LiNiO}_{2}$ powder with a submicron particle size and narrow size distribution. It is suggested that this process can be applied to synthesize other types of cathode materials in lithium ion
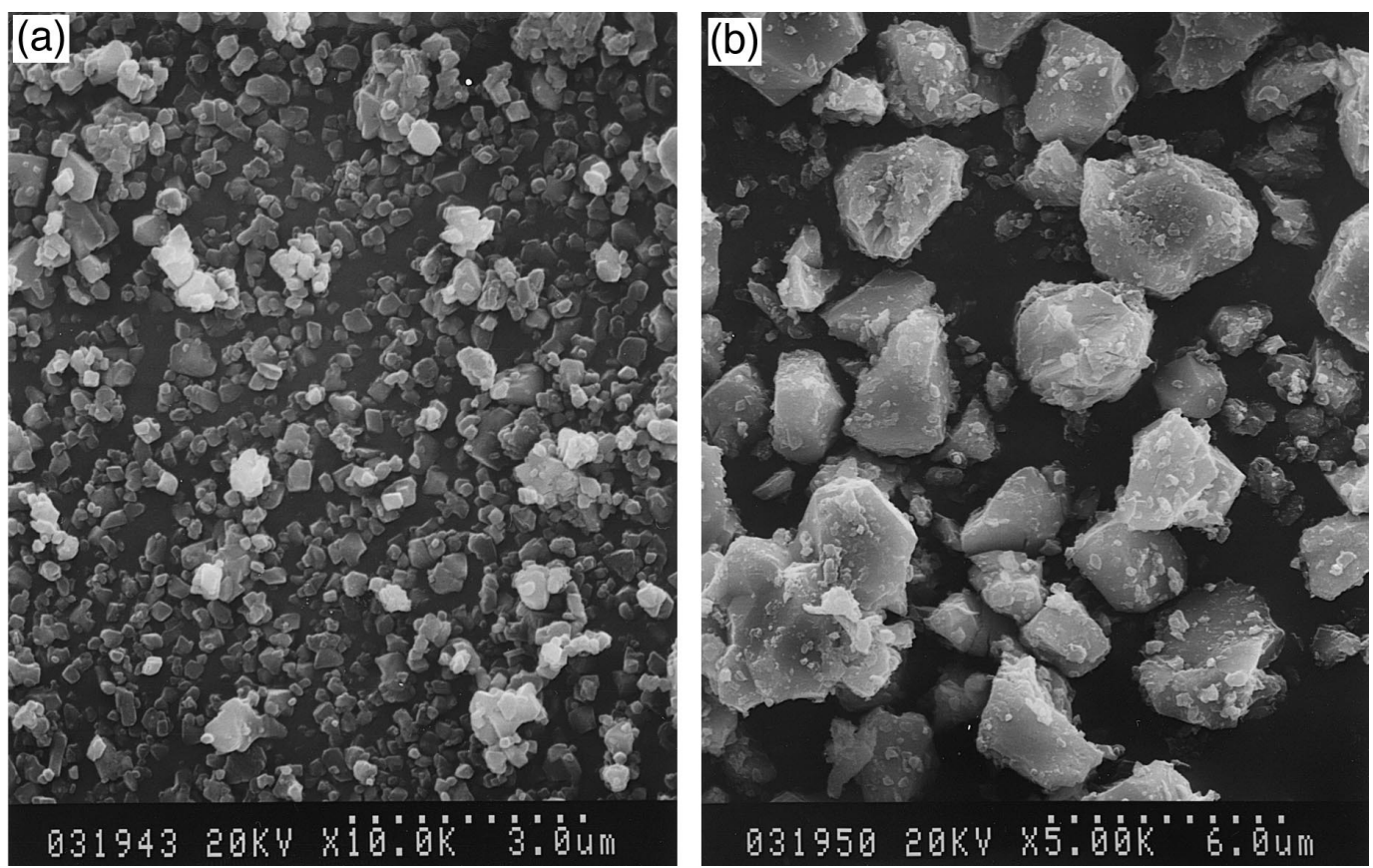

Fig. 5. SEM photographs of $\mathrm{LiNiO}_{2}$ powder prepared by (a) the emulsion process at $800^{\circ} \mathrm{C}$ for $2 \mathrm{~h}$, and (b) the conventional solid state reaction at $800^{\circ} \mathrm{C}$ for $6 \mathrm{~h}$. 
batteries such as $\mathrm{LiCoO}_{2}$ and $\mathrm{LiMn}_{2} \mathrm{O}_{4}$ powder with precise control of the particle size and particle morphology.

\section{Conclusions}

(i) Monophasic $\mathrm{LiNiO}_{2}$ powder has been successfully prepared by the developed emulsion process in which the aqueous solutions of lithium and nickel ions were emulsified in kerosene oil phase using sorbitan monooleate as surfactant.

(ii) The $\mathrm{LiNiO}_{2}$ ceramic powder prepared by the emulsion process has a uniform morphology and submicron particle size $(0.2-0.3 \mu \mathrm{m})$ which is much finer than that of the powder synthesized by the conventional solid state reaction.

(iii) This novel process effectively enhances the homogeneity of the constitute cations in precursors, thereby reducing reaction time as well temperature for obtaining highly crystalline single-phase $\mathrm{LiNiO}_{2}$.

\section{References}

[1] J.R. Dahn, U. von Sachen, C.A. Michal, Solid State Ionics 44 (1990) 87.

[2] T. Ohzuku, H. Komori, M. Nagayama, K. Sawai, T. Hirai, Chem. Express 6 (1991) 161.

[3] W. Ebner, D. Fouchard, L. Xie, Solid State Ionics 69 (1994) 238.

[4] T. Ohzuku, A. Ueda, M. Nagayama, J. Electrochem. Soc. 140 (1993) 1862.

[5] A. Rougier, P. Gravereau, C. Delmas, J. Electrochem. Soc. 143 (1996) 1168.

[6] R. Kanno, H. Kubo, Y. Kawamoto, T. Kamiyama, F. Izumi, Y. Takeda, M. Takano, J. Solid State Chem. 110 (1994) 216.

[7] J. Morales, C. Perez-Vicente, J.L. Tirado, Mater. Res. Bull. 25 (1990) 623.

[8] M.S. Whittingham, R. Chen, T. Chirayil, P. Zavalij, Solid State Ionics 94 (1997) 227.

[9] C.H. Lu, C.H. Yeh, Mater. Lett. 33 (1997) 129.

[10] C.H. Lu, Y.P. Wu, Mater. Lett. 27 (1996) 13.

[11] L.D. Dyer, B.S. Borie, G.P. Smith, J. Am. Chem. Soc. 76 (1954) 1499.

[12] Y.K. Sun, I.H. Oh, J. Mater. Sci. Lett. 16 (1997) 30. 